\title{
LLLT FOR FEMALE INFERTILITY: NO LONGER JUST A DREAM
}

\author{
Toshio Ohshiro MD PhD
}

Here we all are, dear readers, reading the third issue of the current $24^{\text {th }}$ volume of our journal. Normally at this time, the heat and humidity of summer are slowly giving way the cooler nights which welcome early autumn. However, a rather abrupt transition was seen earlier this month when the north-east of Japan was literally inundated by the aftermath of Typhoon Etau. The Kinugawa River broke its banks in the southern part of Tochigi Prefecture, north of Tokyo, and the town of Joso was completely flooded, with whole houses being carried away, some residents left clinging to their roofs, awaiting rescue. Trains were cancelled due to the flooding and many major roads were closed causing disruption to hundreds who could not return home from Tokyo, or who could not get back to Tokyo from the affected scenic spots.

It seems that we are all experiencing more and more incidents of severe weather this year, like the typhoons that have lashed the Philippines, all said to be due to the climate warming phenomenon. No matter what the cause, we at the Laser Therapy editorial office ask you all to join us and spare a thought for those poor souls worldwide who have been a victim of severe weather or other natural disasters this year.

On a happier note, the Japanese semi (cicadas) are chirping away during their short but frenetic 72 hours of life above the ground, but the droning "meeee-meeee" semi of high summer is giving way to the chant of the "tsuku-tsuku-boshi" semi of late summer and early autumn. When we hear that song, we know that autumn is just around the corner and breathe a sigh of relief that the hot and humid days of our Japanese summer are almost over. Let us hope the same applies to the typhoon season!

\section{$10^{\text {th }}$ Memorial congress of the Japan Society for Laser Reproduction (JaSLaR)}

This keystone event took place on March $29^{\text {th }}$ this year, in the Toshi Center Hotel in Tokyo. The JaSLaR Congress President was Dr Toshio Hara, the Director of the Hara Medical Clinic, ably assisted by the meet- ing Chairman, Dr Aisaku Fukuda, Director of the IVF Osaka Clinic. No report has been submitted to the journal, but the author feels that this event should be highlighted as another solid step on the pathway to seeing LLLT recognized as a mainline approach to helping infertile women bear children in a totally noninvasive way, used in tandem with all other assisted reproduction techniques (ARTs).

The Japanese Society for Laser Reproduction (JaSLaR) was inaugurated to champion the cause of LLLT for infertility through education and research, both basic and clinical. The first JaSLaR meeting was held in 2006 under the Presidency of the author, and at the $2^{\text {nd }}$ meeting, Laser Therapy was voted in as the official JaSLaR journal. Successful and ever-larger meetings have been held annually, culminating in the $10^{\text {th }}$ Memorial Meeting held in Tokyo in March of this year, selected abstracts from which are published elsewhere in this issue.

Towards the aim of placing JaSLaR and LLLT for infertility in the spotlight, the author has selected a broad range of topics and had the abstracts translated into English, forming part of the Table of Contents of this $3^{\text {rd }}$ issue of Volume 24. These will provide a window for the reader to see some of the sterling work, background science and excellent results of the use of LLLT for female infertility. The invited contribution by Tracey Griffiths, Senior Clinical Scientist, Oxford Fertility Unit, United Kingdom is particularly interesting. Ms Griffiths is a prolific author and researcher in the infertility field, with a number of publications.

LLLT for infertility has a particular target in Japan, where the rapidly graying population is being negatively echoed by the rapidly-dropping birth rate. Giving birth at a later stage is associated with problems for both mother and child, but for older would-be mothers the greatest problem is infertility, sometimes severe. The application of low level laser therapy (LLLT) is a potentially effective treatment for severe infertility, and has an interesting history.

Some 20 years ago in 1995, the author was treat- 
ing a 55-year-old menopausal female patient in his pain clinic for severe lower back pain. After a few sessions, her back pain was successfully removed, but she returned later to the clinic complaining of vaginal bleeding: she was followed for a week, and it stopped spontaneously. Four weeks later, the bleeding had started again but stopped after a week or so, and this continued for succeeding months. In fact, it was found that the patient had incidentally been brought out of menopause by the LLLT sessions for her lower back pain. Exactly the same phenomenon subsequently occurred in another female patient attending the author's pain clinic. Following the involvement of a leading gynecology professor in Sanno Hospital, an extended trial on LLLT using the author's proximal priority technique was performed in 562 infertile patients, 122 of whom became pregnant resulting in 62 "laser babies". LLLT on its own accounted for 28 of the 122 pregnancies, and LLLT plus ARTs for the remaining 94. This study has been reported in detail in a previous issue of the journal (Ohshiro T: Personal overview of the application of LLLT in severely infertile Japanese females. Laser Therapy, (2012); 21: 97-103).

\section{1st Meeting of the International Society for Laser Surgery and Medicine}

The $21^{\text {st }}$ ISLSM meeting was successfully held in Indore, India, on August $20^{\text {th }}$ to the $22^{\text {nd }}$, in the Hotel Fortune Landmark, Indore, with Dr Sharon Rau as Meeting President, and Prof Krishna Rau as Chairman, Organizing Committee. This means that Dr Sharon Rau is now the President of the ISLSM, so sincere congratulations to her, and we wish her a happy and fruitful two years in this role. We had hoped to have a report on the meeting from Prof Rau, but we will expect that in time for publication in the next issue of the journal.

We did, however, receive a report from Professor Ming Chien Kao, who very generously offered up to 10 travel grants for successful papers. The selection committee, including Prof. K. Rau, Prof. Narong Nimsakul, Prof. K. Sharon, Prof. L. Longo, and Prof. M.C. Kao, carefully screened all the papers which were presented in the Congress, and finally 7 papers were selected to win the travel grants, as follows:

\section{Author}

Dr Dana York

Dr Khageswar Sahu

Dr Li Ling Yu

Dr N Manickavel

Dr Peter Hasan

Dr Rakim Dasgupta

Dr Yogesh Varma

\section{Title}

LLLT and mercury detoxification

Antimicrobial photodynamic therapy for wound healing

Acute suppurative parotitis treatment by diode laser combined with Er:YAG laser

Benefit of laser application in the treatment hemorrhoids over standard treatments Fractional CO2 laser with PRP application

Application of optical tweezers in biomedical diagnosis

Noninvasive monitoring of wounds using optical coherence tomography

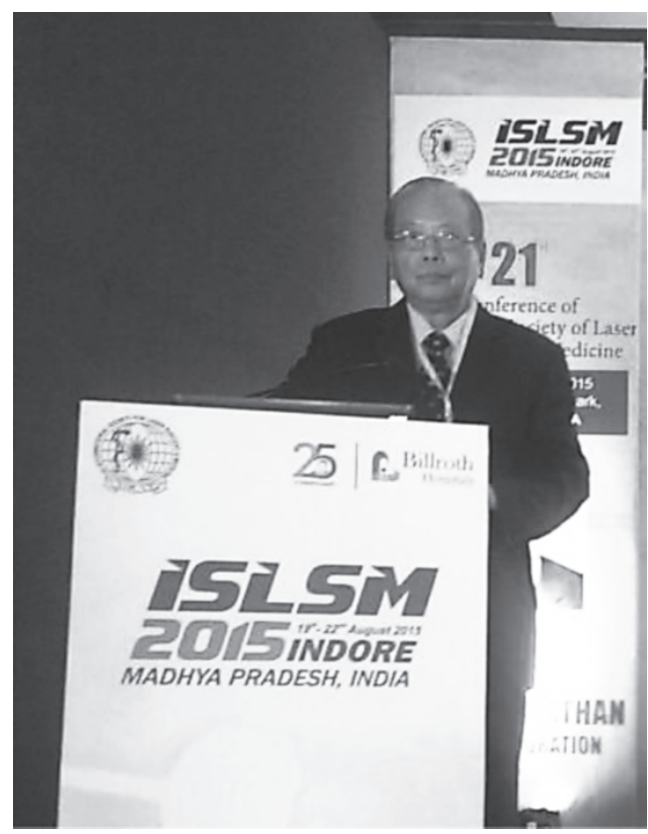

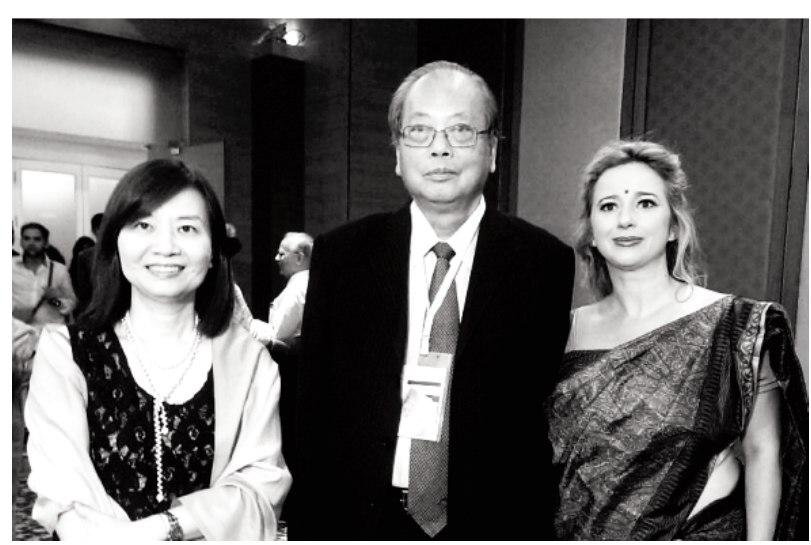

Ming Chien Kao travel grants:

Left: Prof. Ming Chien Kao at the podium.

Above: Prof. Kao with two of the winners, Dr Li Ling Yu on Dr Kao's left and Dr Dana York on the right, dressed in a traditional sari 
Our congratulations to the selected winning authors, and our continued thanks to Prof Kao for his tremendous generosity, bearing in mind that he has also underwritten the Ming Chien Kao Award for Young Authors, awarded via Laser Therapy.

\section{End Notes}

Can I please remind you that the journal cannot exist without a constant flow of top-quality articles, so please, share your clinical and research experience with our readers, your colleagues. Finally please also remember that Laser Therapy is once again offering the 2015 Toshio Ohshiro - Laser Therapy Best Papers
Awards with worthwhile cash prizes, and the Ming Chien Kao Award for Young Authors: for details see the information page elsewhere in this issue of the journal. You have until the deadline for 24:4 to get your article in, and win ..... if you're not in it, you can't win it!.

For those of us in the Northern Hemisphere, let's enjoy the last days of summer as we head into the mellow days of autumn, hopefully without any more severe natural disasters, or for our antipodean colleagues, enjoy the rebirth of spring. Happy writing! Tokyo, September 2015 